\title{
ANALISIS FAKTOR-FAKTOR PRODUKSI YANG MEMPENGARUHI PRODUKSI KOPI ROBUSTA DI KECAMATAN SUMOWONO KABUPATEN SEMARANG
}

\section{Analysis of Determinant Factors Influencing Robusta Coffee Production in Sumowono District Regency of Semarang}

\author{
M.D. Isyariansyah, D. Sumarjono, K. Budiraharjo \\ Program Studi S1 Agribisnis Fakultas Peternakan dan Pertanian \\ Universitas Diponegoro, Semarang \\ Email : danarisya@yahoo.co.id
}

Diterima 28 Agustus 2017, disetujui 15 Februari 2018

\begin{abstract}
ABSTRAK
Penelitian bertujuan untuk menganalisis jumlah produksi rata-rata kopi Robusta petani di Kecamatan Sumowono, menganalisis faktor-faktor yang berpengaruh terhadap produksi kopi Robusta di Kecamatan Sumowono, serta untuk mengetahui faktor yang paling berpengaruh terhadap produksi kopi Robusta di Kecamatan Sumowono. Lokasi penelitian ditentukan secara purposive. Metode yang digunakan adalah metode survei dan pemilihan sampel ditentukan dengan memilih 25 responden setiap 3 desa di Kecamatan Sumowono, sehingga berjumlah 75 responden. Hasil penelitian menunjukan bahwa produksi rata-rata kopi Robusta petani di Kecamatan Sumowono sebesar $1.617 \mathrm{~kg} / \mathrm{ha}$ lebih tinggi dari produksi rata-rata kopi Robusta petani di provinsi Jawa Tengah sebesar $1.200 \mathrm{~kg} / \mathrm{ha}$, dan Nasional yaitu sebesar $855 \mathrm{~kg} / \mathrm{ha}$. Secara serempak luas lahan, jumlah pohon, jumlah pupuk kandang, jumlah pupuk NPK dan penggunaan tenaga kerja secara serempak berpengaruh nyata terhadap produksi kopi Robusta, sedangkan secara parsial hanya jumlah, pupuk kandang dan tenaga kerja yang berpengaruh nyata terhadap produksi kopi Robusta. Tenaga kerja adalah faktor yang paling berpengaruh terhadap faktor produksi kopi Robusta di Kecamatan Sumowono.
\end{abstract}

Kata Kunci : Produksi, faktor produksi, kopi Robusta.

\begin{abstract}
This research aimed to analyze the average of Robusta coffee production in Sumowono District, analyze the factors of production to Robusta coffee production in Sumowono District and to know the most influenced factor on Robusta coffee production in Sumowono District. Survey method was used to select 25 respondents from 3 Villages in Sumowono, so the result 75 respondent. Respondents were taken by simple random sampling. The result of the research showed that the average of Robusta coffee in Sumowono District was $1.617 \mathrm{~kg} / \mathrm{ha}$. It was higher than the production average of coffee in province of central java which are $1.200 \mathrm{~kg} / \mathrm{ha}$, and National which are $855 \mathrm{~kg} / \mathrm{ha}$. The land area, the number of seeds, the amount of manure, the amount of NPK fertilizer and the use of labor simultaneously were significantly influenced to Robusta coffee production, while the variable of the number of seeds, the amount of manure, and the use of labor showed partially significant effect to the production on Robusta coffee. Labor was the most influenced factor to Robusta coffee production in Sumowono District.
\end{abstract}

Keywords : Production, production factors, Robusta coffee 


\section{PENDAHULUAN}

Indonesia adalah negara yang di lalui garis khatulistiwa dengan cuaca serta musim relatif stabil dan tanah yang subur. Indonesia terdiri atas beberapa pulau, yang membuat produk kopinya kaya rasa dan aroma. Interaksi jenis tanah, iklim, varietas kopi, dan metode pengolahanya membuat kopi di Indonesia paling menarik di dunia. Kopi Robusta (Coffea canephora) mulai diperkenalkan di Indonesia Tahun 1900 untuk pengganti kopi Arabika yang hancur akibat serangan karat daun. Kopi Robusta lebih tahan terhadap organisme pengganggu tanaman sehingga dianggap sebagai alternatif yang tepat, (Rukmana, 2014). Pada tahun 2014, tanaman kopi Robusta di Kecamatan Sumowono memiliki memiliki jumlah produksi kopi Robusta terbesar di Kabupaten Semarang. (BPS Kabupaten Semarang, 2014).

Produksi adalah hasil akhir dari proses atau aktivitas ekonomi yang memanfaatkan beberapa masukan input. Kegiatan produksi diartikan sebagai aktivitas dalam menghasilkan output dengan menggunakan teknik produksi tertentu untuk mengolah atau memproses input sedemikian rupa (Sukirno, 2002). produksi rata-rata kopi Robusta di provinsi Jawa Tengah sebesar $1.200 \mathrm{~kg} / \mathrm{ha}$, dan Nasional yaitu sebesar $855 \mathrm{~kg} / \mathrm{ha}$ (Direktorat Jendral Perkebunan, 2016). Fakorfaktor produksi merupakan benda atau jasa yang disediakan oleh alam atau dihasilkan oleh manusia dan digunakan untuk menghasilkan berbagai macam barang atau jasa. Faktor-faktor produksi yang umum digunakan di bidang pertanian antara lain lahan, bibit, pupuk, pestisida, tenaga kerja dan lain sebagainya (Marhasan, 2005). Faktor faktor produksi terhadap produksi kopi Robusta yang digunakan dalam penelitian ini adalah luas lahan, bibit, pupuk kandang, pupuk NPK dan tenaga kerja.

Tujuan dari penelitian ini adalah 1) menganalisis jumlah produksi rata-rata kopi Robusta petani di Kecamatan Sumowono 2) menganalisis faktor-faktor yang berpengaruh terhadap produksi kopi Robusta di Kecamatan Sumowono. 3) mengetahui faktor yang paling berpengaruh terhadap produksi kopi Robusta di Kecamtan Sumowono.

\section{METODE PENELITIAN}

\section{Waktu dan Lokasi Penelitian}

Penelitian dilaksanakan pada bulan Maret hingga April 2017 di Kecamatan Sumowono Kabupaten Semarang. Lokasi penelitian ini di tentukan secara purposive, berdasarkan pertimbangan bahwa Kecamatan Sumowono memiliki produksi kopi Robusta terbesar di Kabupaten Semarang. Sugiyono (2010) menyatakan bahwa purposive adalah suatu teknik penentuan lokasi penelitian secara sengaja berdasarkan pertimbanganpertimbangan tertentu.

\section{Metode Penelitian dan Penentuan Sampel}

Metode yang digunakan dalam penelitian ini adalah metode survei. Kecamatan Sumowono terdiri dari 16 desa. Penentuan lokasi penelitian dilakukan secara purposive berdasarkan kriteria desa yang paling berpotensial di Kecamatan Sumowono menurut Balai Penyuluhan Pertanian Kecamatan Sumowono. Terpilih 3 Desa yaitu, Desa Ngadikerso, Desa Kebonagung dan Desa Pledokan. Setiap Desa dipilih satu kelompok tani. Satu kelompok tani diambil 25 responden, sehingga berjumlah 75 responden.

\section{Metode Analisis Data}

Data yang dikumpulkan dalam peneilitian ini adalah data primer dan data sekunder. Data primer adalah data yang diperoleh atau dikumpulkan secara langsung dari lapangan oleh orang yang melakukan penelitian. Data primer dalam penelitian ini diperoleh dengan cara wawancara dengan panduan menggunakan kuesioner. Data Sekunder dikumpulkan dari sumber-sumber yang telah ada seperti Dinas Perkebunan dan berbagai sumber di tabulasi dan di analisis data (Hasan, 2004).

Data sebelum dianalisis terlebih dahulu diuji kenormalanya. Pengujian kenormalan data dengan menggunakan model kolmogorov-smirnov dengan bantuan 
program SPSS (Statistical product and Service Solutions). Jika hasil uji normalitas data menunjukan nilai signifikansi $\geq 0,05$ maka data normal.

Jumlah Produksi rata-rata kopi Robusta petani, akan di analisis uji beda (uji one sample $t$-test) dengan membandingkan produksi rata-rata kopi Robusta di Kecamatan Sumowono dengan produksi kopi rata-rata di Provinsi Jawa Tengah dan Nasional. Faktorfaktor produksi yang berpengaruh terhadap produksi kopi Robusta di analisis menggunakan persamaan regresi dianalisis dengan model fungsi produksi Cobb-Douglas. Model Persamaan $\left(\mathrm{Y}=\mathrm{aX} 1^{\beta 1} \cdot \mathrm{X}^{\beta 2} \cdot \mathrm{X} 3^{\beta 3}\right.$. $\mathrm{X} 4^{\beta 4} \cdot \mathrm{X} 5^{\beta 5} \cdot \mathrm{e}^{\mathrm{u}}$

Keterangan :

$\mathrm{Y}=$ Jumlah produksi kopi
$(\mathrm{kg} /$ tahun $)$
$\beta 1, \beta 2 \ldots \ldots \beta$

\section{pohon)}

$\mathrm{X} 3=$ Pupuk Kandang (kg/tahun)

X4 $=$ Pupuk NPK (kg/tahun)

X5 $=$ Tenaga kerja (HKP/tahun);

1 Pria $=1$ HKP, 1 Wanita $=0,7$ HKP, 1 anak $=0,5 \mathrm{HKP}$ )

$$
\begin{array}{ll}
\mathrm{e} & =\text { Logaritma natural }(\mathrm{e}=2,178) \\
\mathrm{u} & =\text { Kesalahan/error }
\end{array}
$$

Analisis model pada persamaan Dari persamaan 1 di transformasi ke Ln supaya bisa di selesaikan dengan SPSS dan bisa diketahui elastisitasnya :

$\operatorname{LnY}=\operatorname{Ln} a+\beta 1 \operatorname{LnX} 1+\beta 2 \operatorname{LnX} 2+\beta 3 \operatorname{LnX} 3$ $+\beta 4 \operatorname{LnX} 4+\beta 4 \operatorname{LnX} 4+\beta 5 \operatorname{LnX} 4+\mathrm{Ut}$

Ln e.

Persamaan yang telah diperoleh dilanjutkan dengan uji asumsi klasik dan uji analisis regresi linier berganda. Uji asumsi klasik terdiri dari uji multikolinieritas, uji heterokedastisitas dan uji autokorelasi. Sedangkan uji analisis regresi linier berganda yang terdiri dari uji koefisien determinasi, uji F (serempak) dan uji t (parsial).

Hasil pendugaan pada fungsi Cobb-
Douglas akan menghasilkan koefisien regresi. Jadi besarnya $\beta$ pada persamaan dua adalah angka elastisitas. Jumlah dari elastisitas adalah merupakan ukuran returns to scale. dengan demikian, kemungkinan ada 3 alternatif, yaitu (Soekartawi, 2003) :

1.Decreasing returns to scale yaitu jika $\beta<1$ artinya tambahan hasil yang semankin menurun atas skala produksi, kasus dimana output bertambah dengan proporsi yang lebih kecil daripada input.

2.Constant returns to scale, jika $\beta=1$ artinya tambahan hasil yang konstan atas skala produksi, bila semua input naik dalam proposi yang tepat sama.

3.Increasing returns to scale jika $\beta>1$ artinya tambahan hasil yang meningkat atas skala produksi. Output bertambah dengan proporsi yang lebih besar dari input.(Soekartawi, 2003).

\section{HASIL DAN PEMBAHASAN}

\section{Keadaan Umum Daerah Penelitian}

Kecamatan Sumowono adalah salah satu dari 19 Kecamatan yang ada di Kabupaten Semarang. Kecamatan Sumowono terletak di ujung barat Kabupaten Semarang yang berbatasan langsung dengan dua Kabupaten, yakni Kendal dan Kabupaten Temanggung. Disebelah utara Kecamatan Sumowono berbatasan dengan Kabupaten Kendal, disebelah timur berbatasan dengan Kecamatan Bandungan dan Kecamatan Jambu, di sebelah selatan berbatasan dengan Kabupaten Temanggung dan Kecamatan Jambu, serta disebelah barat berbatasan dengan Kabupaten Kendal dan Temanggung.

Tinggi tempat 900 Kecamatan Sumowono memiliki luas wilayah sebesar $55.630 \mathrm{Km}^{2}$ yang terdiri atas 16 desa. 60 dusun, 60 rukun warga dan 219 rukun tetangga, dengan jumlah penduduk sebanyak 31.192 jiwa dengan jumlah penduduk lakilaki sebanyak 15.732 jiwa dan penduduk perempuan sebesar 15.460 jiwa.

Iklim di wilayah Sumowono tidak berbeda dengan kondisi di sebagian wilayah Kabupaten Semarang pada umumnya. Suhu mencapai $15^{0} \mathrm{C}-24^{0} \mathrm{C}$, kelembapan udara 
mencapai 35\%-50\%. Curah hujan Kabupaten Semarang mencapai $1.683 \mathrm{~mm}$. Kondisi tersebut merupakan kondisi yang cocok untuk tanaman kopi. Hal ini sesuai dengan pendapat Kandari et al (2013) yang menyatakan bahwa tanaman kopi tumbuh optimum di tempat dengan curah hujan $2.000-3.000 \mathrm{~mm} /$ tahun.

\section{Karakteristik Responden}

Karakteristik merupakan deskripsi secara umum petani kopi Robusta di Kecamatan Sumowono yang menjadi responden dalam penelitian ini yang dibahas berdasarkan jenis kelamin, usia, dan pendidikan terakhir dan lama berusahatani. Berdasarkan jenis kelamin, karakteristik responden penelitian dapat dilihat pada Ilutrasi 1.

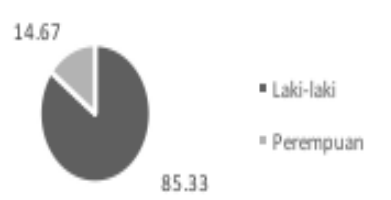

Ilustrasi 1. Karakteristik Responden

Berdasarkan hasil penelitian diketahui bahwa responden laki-laki lebih besar daripada responden perempuan. Responden laki-laki sebanyak 64 jiwa dengan persentase $85,33 \%$ sedangkan responden perempuan sebanyak 11 jiwa dengan persentase 14,67\%. Usia Responden hanya dibatasi pada orang dewasa yang biasanya berusia diatas 20 tahun. Pendidikan responden yaitu antara SD SMP dan SMA. responden terbanyak pendidikan terakhir adalah SD dengan $82,67 \%$. Pendidikan sangat penting untuk menentukan prilaku seseorang. Lama berusahatani di Kecamatan Sumowono terbanyak yaitu berada diantara 10-20 tahun dengan 41,33. Semakin lama pengalaman berusahatani maka akan semakin baik dalam berusahatani kopi Robusta.

\section{Produksi dan faktor produksi}

Jumlah rata-rata produksi kopi Robusta petani di Kecamatan Sumowono dalam satu tahun sebesar $1.617 \mathrm{~kg} / \mathrm{th}$. Angka tersebut lebih tinggi dari rata-rata produksi kopi Robusta di Provinsi Jawa Tengah sebesar
$1.200 \mathrm{~kg} / \mathrm{ha}$, dan Nasional yaitu sebesar 855 $\mathrm{kg} / \mathrm{ha}$ (Dirjen Perkebunan, 2016). Angka tersebut juga lebih besar dari rata-rata produksi kopi Robusta di lereng gunung Tambora. Menurut aklimawati et al (2014) menyatakan bahwa rata-rata produksi kopi Robusta di lereng gunung tambora yaitu $1.000 \mathrm{~kg} / \mathrm{ha}$.

Berdasarkan Tabel 1. diperoleh hasil bahwa dengan rata-rata luas lahan kopi Robusta petani di Kecamatan Sumowono sebesar 0,72 ha, dapat menanam jumlah pohon sebanyak 986 pohon. Penggunaan ratarata jumlah pupuk kandang sebesar 2.487 $\mathrm{kg} / \mathrm{th}$, sehingga dalam satu tahun membutuhkan $3 \mathrm{~kg}$ pupuk kandang/pohon. Sedangkan penggunaan rata-rata pupuk NPK sebesar $90 \mathrm{~kg} / \mathrm{th}$. sehingga dalam satu tahun membutuhkan 0,09 Kg/pohon. Penggunaan pupuk kandang dan pupuk NPK sangat penting untuk meningkat kan produksi kopi Robusta. Penggunaan rata-rata tenaga kerja dalam 1 tahun yaitu berjumlah 469 HKP.

\section{Metode Analisis Data}

Berdasarkan hasil uji normalitas data menggunakan Kolmogorov - Smirnov diperoleh bahwa uji normalitas data menunjukan nilai signifikansi $>0,05$, maka data normal, hal ini sesuai dengan pendapat Ghozali (2009) yang menyatakan bahwa jika probabilitas signifikansi $>0,05$ maka data berdistribusi normal.

Setelah uji normalitas data normal maka dilakukan uji one sample t-test. Uji one sample t-test dilakukan untuk membandingkan antara jumlah rata-rata produksi petani kopi Robusta di Kecamatan Sumowono sebesar $1.617 \mathrm{~kg} / \mathrm{ha}$ dengan ratarata produksi kopi Robusta di Provinsi Jawa Tengah sebesar $1.200 \mathrm{~kg} / \mathrm{ha}$, dan Nasional yaitu sebesar $855 \mathrm{~kg} / \mathrm{ha}$. Berdasarkan hasil penelitian, diperoleh hasil bahwa nilai signifikansi sebesar 0,000. Sehingga nilai sig $\leq 0,05$. Hasil analisis menyatakan bahwa terdapat perbedaan nyata antara jumlah ratarata produksi kopi Robusta petani di kecamatan sumowono dengan produksi ratarata kopi Robusta di indonesa. 
Faktor-faktor Terhadap Produksi Kopi Robusta di Kecamatan Sumowono

Berdasarkan hasil analisis data diperoleh nilai koefisien regresi untuk masing-masing faktor produksi pada Tabel 2. Persamaan fungsi produksi dituliskan sebagai berikut : $\operatorname{LnY}=-4,387-0,268 \operatorname{LnX}_{1}+0,549 \operatorname{LnX}_{2}+$ $0,466 \operatorname{LnX}_{3}-0,146 \operatorname{LnX}_{4}+0,795 \operatorname{LnX}_{5}$

Bentuk persamaan.dalam model CobbDouglas sebagai berikut :

$\mathrm{Y}=$

$0,237 \mathrm{X}_{1}{ }^{0,268} \cdot \mathrm{X}_{2}{ }^{0,549} \cdot \mathrm{X}_{3}{ }^{0,466} \cdot \mathrm{X}_{4}{ }^{0,146} \cdot \mathrm{X}_{5}{ }^{0,795}$

Selanjutnya persamaan diuji dengan asumsi klasik yang meliputi normalitas error, uji multikolinieritas, uji heterokedastisitas dan uji autokorelasi.

Hasil menunjukan bahwa data yang diuji tidak terdapat multikolinieritas karena nilai VIF semua variabel penduga kurang dari 10 . Nilai VIF $X_{1}$ hungga $X_{5}$ secara berturut turut adalah 9,863, 6,237, 8,053, 7,937, dan 7,505. Gujarati (2003) menyatakan bahwa uji multikolinieritas dapat dilihat dari output coliniearity statistics. Jika nilai VIF $<10$ maka tidak terjadi multikorelasi,. Berdasarkan hasil uji heteroskedastisitas menunjukan bahwa semua variabel independen tidak terjadi heterokedastisitas, karena nilai X1 hingga X5 secara berturut-turut 0,299, 0,183, $0,843,0,600$, dan 0,689. Berdasarkan hasil uji autokorelasi menunjukan bahwa data yang diuji tidak terjadi autokorelasi, karena nilai Durbin-Watson sebesar 1,496 dan berada di antara $-2<$ DW $<2$ (Santoso, 2001).

Pengaruh penggunaan faktor produksi kopi Robusta terhadap jumlah produksi kopi Robusta di Kecamatan Sumowono Kabupaten Semarang dapat diketahui melalui nilai adjusted $\mathrm{R}$ square, uji $\mathrm{F}$ dan uji t pada Tabel 2 yang dijelaskan sebagai berikut:

1. Hal ini menunjukan bahwa $89 \%$ produksi kopi Robusta di Kecamatan Sumowono dijelaskan oleh variabel luas lahan, jumlah pohon, pupuk kandang, pupuk NPK dan tenaga kerja. Sedangkan sisanya sebesar $11 \%$ dijelaskan oleh variabel lain di luar model. Hal ini sesuai dengan pendapat
Tabel 1. Rata-rata Faktor-faktor Produksi Kopi Robusta Petani di Kecamatan Sumowono

\begin{tabular}{lllc}
\hline No & Faktor Produksi & \multicolumn{1}{c}{ Satuan } & Rata-rata \\
\hline 1. Luas lahan & $\mathrm{Ha}$ & 0,72 \\
2. Jumlah Pohon & Pohon & 986 \\
3. Pupuk Kandang & $\mathrm{Kg}$ & 2.487 \\
4. Pupuk NPK & $\mathrm{Kg}$ & 90 \\
5. & Tenaga Kerja & $\mathrm{HKP}$ & 469
\end{tabular}

Sumber: Data Primer Penelitian, 2017.

Ramadhani (2011) yang menyatakan bahwa semakin besar nilai $\mathrm{R}^{2}$ mendekati nilai satu, maka semakin baik hasil regresi tersebut.

2. Berdasarkan analisis uji F, dapat diketahui bahwa nilai signifikansi sebesar 0,000 . Nilai tersebut signifikan karena $\mathrm{p}<0,05$, sehingga $\mathrm{H}_{0}$ ditolak dan $\mathrm{H}_{1}$ diterima. Hal ini menunjukan bahwa variabel-variabel bebas yang diamati yaitu luas lahan, jumlah pohon, pupuk kandang, pupuk NPK dan tenaga kerja secara bersama-sama berpengaruh nyata terhadap produksi kopi Robusta di Kecamatan Sumowono.

3. Berdasarkan analisis uji t, dapat diketahui bahwa secara parsial jumlah pohon, pupuk kandang dan tenaga kerja berpengaruh nyata $(p<0,05)$ terhadap produksi kopi Robusta., sedangkan variabel luas lahan dan pupuk NPK tidak berpengaruh nyata terhadap produksi kopi Robusta $(\mathrm{p}>0,05)$.

\section{Elastisitas Produksi dan faktor produksi}

Berdasarkan perhitungan elastisitas produksi yang dilakukan dengan menjumlahkan koefisien regresi dari fungsi persamaan Cobb-Douglas, maka didapatkan elastisitas produksi untuk usahatani kopi Robusta di Kecamatan Sumowono adalah sebesar 1,396. Elastisitas produksi mempunyai nilai lebih besar dari satu, artinya tingkat pengembalian usaha dari usahatani kopi Robusta yang dijalankan di Kecamatan 
Sumowono berada di tingkat increasing return to scale artinya tingkat pengembalian terhadap skala usaha meningkat, karena jumlah output yang dihasilkan mengalami peningkatan dari jumlah input yang digunakan. Hal ini sesuai dengan pendapat Soekartawi (2003) yang menyatakan bahwa Increasing returns to scale jika $\beta>1$ artinya tambahan hasil yang meningkat atas skala produksi. Output bertambah dengan proporsi yang lebih besar dari input.

Secara parsial yang berpengaruh nyata yaitu, jumlah pohon, pupuk kandang dan tenaga kerja adalah sebagai berikut :

\section{Jumlah pohon (X2)}

Berdasarkan hasil penelitian diketahui bahwa jumlah pohon secara parsial berpengaruh nyata terhadap produksi kopi Robusta. Koefisien regresi berganda yang diperoleh sebesar 0,549, artinya setiap penambahan jumlah pohon sebesar $1 \%$ akan meningkatkan produksi sebesar 0,549\%. Hal ini menunjukan semakin banyak jumlah pohon maka semakin tinggi produksi kopi Robusta. Banyaknya jumlah pohon dilihat dari jarak tanamnya. jarak tanam di Kecamatan Sumowono yaitu rata-rata $2,75 \mathrm{x}$ $2,75 \mathrm{~m}$. Hal ini sesuai dengan pendapat Suwarto et al. (2000) yang menyatakan bahwa jarak tanam ideal yang di anjurkan adalah 2,75 m x 2,75 m untuk kopi Robusta.

\section{Pupuk kandang (X3)}

Berdasarkan hasil penelitian diketahui bahwa pupuk kandang secara parsial berpengaruh nyata terhadap produksi kopi Robusta, Koefisien regresi berganda yang diperoleh sebesar 0,466. Hal ini menunjukan setiap penambahan jumlah pohon sebesar $1 \%$ akan meningkatkan produksi sebesar $0,466 \%$, artinya pupuk kandang mempengaruhi produksi kopi Robusta. Penggunaan pupuk kandang di Kecamatan Sumowono apabila digunakan dengan jumlah banyak akan memperbaiki kesuburan tanah dan akan meningkatkan proses produksi. Hal ini sesuai dengan pendapat Kadir dan Karo (2006) yang menyatakan bahwa limbah kotoran ternak / pupuk kandang mampu memperbaiki pertumbuhan dan produktivitas tanaman kopi. Hal ini karena pemberian pupuk mempunyai pernanan besar dalam mendukung perbaikan sifat fisik, kimia, biologi tanah, serta meningkatkan ketersediaan hara dalam tanah.

\section{Tenaga kerja (X5)}

Berdasarkan hasil penelitian diketahui bahwa tenaga kerja secara parsial berpengaruh nyata terhadap produksi kopi Robusta. Koefisien regresi berganda yang diperoleh sebesar 0,795, artinya setiap penambahan tenaga kerja sebesar $1 \%$ akan meningkatkan produksi sebesar 0,795\%. Hal ini berarati bahwa penambahan jumlah tenaga kerja akan meningkatkan produksi kopi

Tabel 2. Hasil Analisis Faktor-Faktor yang Mempengaruhi Produksi

\begin{tabular}{lcrc}
\hline \multicolumn{1}{c}{ Variabel } & Koefisien Regresi & $\mathrm{T}$ & \multicolumn{1}{c}{ Sig. } \\
\hline Konstanta & $-4,387$ & $-2,901$ & 0,005 \\
Luas Lahan (X1) & $-0,268$ & $-1,344$ & 0,183 \\
Jumlah Pohon (X2) & 0,549 & 4,876 & $0,000^{*}$ \\
Pupuk Kandang (X3) & 0,466 & 2,707 & $0,009^{*}$ \\
Pupuk NPK (X4) & $-0,146$ & $-0,664$ & 0,509 \\
Tenaga Kerja (X5) & 0,795 & 4,256 & $0,000^{*}$ \\
\hline Jumlah & 1,396 & & 0,890 \\
Adjusted R Square & & & 0,000 \\
F Hitung & & &
\end{tabular}

Sumber: Data Output SPSS (Diolah)

Keterangan: Variabel dalam bentuk logaritma natural/Ln

*: Signifikansi pada taraf $99 \%$ 
Robusta di Kecamatan Sumowono. Hal ini sesuai dengan pendapat Hernanto (1989) yang menyatakan bahwa penggunaan tenaga kerja harus sesuai dengan kebutuhan dari suatu kegiatan usahatani agar mendapatkan produksi yang terus meningkat. Hal ini juga sependapat dengan pendapat Risnandewi (2013) yang menyatakan bahwa penambahan jumlah tenaga kerja akan meningkatkan jumlah produksi kopi Robusta.

\section{SIMPULAN DAN SARAN}

Produksi rata-rata kopi robusta petani di Kecamatan Sumowono sebesar $1.617 \mathrm{~kg} / \mathrm{ha}$. Angka tersebut berbeda nyata atau lebih tinggi dari rata-rata produksi kopi Robusta di Provinsi Jawa Tengah sebesar $1.200 \mathrm{~kg} / \mathrm{ha}$ dan Nasional yaitu sebesar $855 \mathrm{~kg} / \mathrm{ha}$.

Luas lahan, Jumlah pohon, pupuk kandang, pupuk NPK dan penggunaan tenaga kerja secara bersama-sama berpengaruh nyata terhadap produksi kopi Robusta. Secara parsial jumlah jumlah pohon, jumlah pupuk kandang dan penggunaan tenaga kerja berpengaruh nyata terhadap produksi kopi Robusta sedangkan luas lahan dan jumlah pupuk NPK tidak berpengaruh terhadap produksi kopi Robusta

Faktor yang paling berpengaruh terhadap produksi kopi Robusta adalah penggunaan tenaga kerja. Elastisitas produksi di Kecamatan Sumowono berada di tingkat increasing return to scale.

Minimal faktor -faktor produksi tetap di pertahankan. Faktor yang tidak berpengaruh tidak perlu diperhatikan untuk pengelolaan yang lebih baik. Jika luas lahan tetap maka jumlah pohon harus ditambah dengan jarak tanam disesuaikan agar produksi meningkat. Pupuk kandang di tambah dan pupuk NPK harus dikurangi. Tenaga kerja di tambah HKP nya.

\section{DAFTAR PUSTAKA}

Aklimawati, L. Yulianto dan S. Mawardi. 2014. Karakteristik mutu dan agribisnis kopi robusta di Lereng Gunung Tambora, Sumbawa. Pelita Perkebunan. 30 (2): 159 -180 .
Direktorat Jendral Perkebunan. 2016. Statistik Perkebunan Indonesia 2014-2016:Kopi. Direktorat Jendral Perkebunan, Jakarta.

Ghozali, I. 2009. Ekonometrika. Teori Konsep dan Aplikasi dengan SPSS 17. Badan Penerbit Universitas Diponegoro, Semarang.

Gujarati, D. 2003. Ekonometri Dasar, terjemahan Sumarno Zain. Erlangga, Jakarta.

Hasan, I. 2004. Analisis Data Penelitian dengan Statistik. Bumi Aksara, Jakarta.

Hernanto F. 1989. Ilmu Usahatani. Penebar Swadaya, Jakarta.

Kadir, S., dan M.Z Karo. 2006. Pengaruh pupuk organik terhadap pertumbuhan dan produksi kopi arabika, Jurnal Agrivigor. 6 (1) : 85-92.

Kandari, A.M., L. O. Safuan dan L.M. Amsil. 2013. Evaluasi kesesuaian lahan untuk pengembangan tanaman kopi robusta (Coffea canephora) berdasarkan analisis data iklim menggunakan aplikasi sistem informasi geografi. J. Agrotekno. 3 (1) : 9-13

Marhasan. 2005. Analisis Ekonomi Usaha Tani di Indonesia. Skripsi. Universitas Diponegoro. Semarang.

Ramadhani, Y. 2011. Analisis Efisiensi, Skala dan Elastisitas Produksi dengan Pendekatan Cobb-Douglas dan Regresi Berganda. J. Teknologi 4(1): 53-61.

Risnandewi T. 2013. Analisis efisiensi produksi kopi robusta di Kabupaten Temanggung (Studi kasis di Kecamatan Candiroto). J Litbang Provinsi Jawa Tengah, 2(1) : 87-102

Rukmana, H. R. 2014. Untung Selangit dari Agribisnis Kopi. Lily Publisher, Jakarta.

Santoso, S. 2001. Analisis Parametrik dengan SPSS. Exelmultimedia, Jakarta.

Soekartawi, 1993. Prinsip Dasar Manajemen. Pemasaran Hasil-hasil Pertanian Terori dan Aplikasinya, Rajawali Press, Jakarta.

Soekartawi. 2003. Teori Ekonomi Produksi Dengan Pokok Bahasan Analisis Fungsi Cobb-Douglas. PT. Raja Grafindo Persada, Jakarta.

Sugiyono. 2010. Metode Penelitian 
Kuantitatif dan Kualitatif \&RND. Alfabeta, Bandung

Sukirno, S. 2002. Makroekonomi Teori Pengantar. Raja Grafindo Persada, Jakarta.

Suwarto, Y. Octaviyanti dan S. Hermawati. 2014. Top 15 Tanaman Perkebunan. Penebar Swadaya, Jakarta. 